\title{
Entrevista com Gilles Monceau ${ }^{\star}$
}

\author{
Entrevistadores: Eduardo Passos ${ }^{\star \star}$ Estela Scheinvar ${ }^{\star \star \star}$ \\ Marisa Rocha $\star \star \star \star$ Maria Livia do Nascimento ${ }^{\star \star \star \star \star}$ \\ Silvia Tedesco $0^{\star \star \star \star \star \star}$ Teresa Cristina Carreteiro ${ }^{\star \star \star \star \star \star \star}$
}

Tradução: Maria Livia do Nascimento e Teresa Cristina Carreteiro

Rio de Janeiro, 24 de abril de 2006.

Entrevistadores: Você propõe o tema da profissionalização quando discute os conceitos de implicação e sobreimplicação. No final da década de 1980, o tema da implicação modula e aparece o de sobreimplicação. Parece que você está propondo uma outra modulação, que seria de uma implicação universitalizante. Entendi que você está introduzindo uma nova idéia, que é a de sobreimplicação reflexiva, que se faz através do discurso, uma modulação do conceito do abstrato, do discursivo universitalizante, que se dá no espaço da universidade, obrigando todas as profissões a passar não pelo fazer, mas pelo falar. Esse tipo de mais valia produz, exige uma nova forma de resistência.

Gilles Monceau: Acredito que a conexão entre sobreimplicação e reflexibilidade é particularmente muito interessante. Dizer sobreimplicação reflexiva concentra quase todas as contradições desse processo de profissionalização Por definição se eu estou sobreimplicado eu não estou reflexivo. A reflexibilidade que eu falo se vincula à sobreimplicação. Posso simplesmente considerar os dispositivos de análise nos quais os profissionais estão convidados a trabalhar as suas dificuldades práticas pelo discurso, com a idéia que a análise discursiva da prática vai permitir fazer evoluir a própria prática. Esses dispositivos de análise da prática

* Professor do Departamento de Ciências da Educação da Universidade de Paris 8 e coordenador do L'Axe socio-clinique institutionnel de l'équipe de recherche ESSI da mesma universidade.

$\star \star$ Doutor em Psicologia pela Universidade Federal do Rio de Janeiro. Atualmente é professor Associado I da Universidade Federal Fluminense.

$\star \star \star$ Doutora em Educação pela Universidade Federal Fluminense. Professora adjunta do Departamento de Educação da Faculdade de Formação de Professores e do Programa de Pós-Graduação em Políticas Públicas e Formação Humana da Universidade do Estado do Rio de Janeiro e Socióloga do Serviço de Psicologia Aplicada da Universidade Federal Fluminense.

$\star \star \star \star$ Doutora em Psicologia (Psicologia Clínica) pela Pontifícia Universidade Católica de São Paulo e Pós-doutorado em Filosofia e História da Educação pela Unicamp. Atualmente é professor adjunto do Departamento de Psicologia Social e Institucional e pesquisadora no Programa de Pós-Graduação em Psicologia Social na Universidade do Estado do Rio de Janeiro.

$\star \star \star \star \star$ Doutora em Psicologia (Psicologia Social) pela Pontifícia Universidade Católica de São Paulo, pos-doutorado pela Universite de Paris VIII. Atualmente é Professor Adjunto 4 da Universidade Federal Fluminense.

$\star \star \star \star \star \star$ Doutora em Psicologia (Psicologia Clínica) pela Pontifícia Universidade Católica de São Paulo. Atualmente é coordenadora da pós-graduação da Universidade Federal Fluminense e Professor Adjunto IV da Universidade Federal Fluminense.

$\star \star \star \star \star \star \star$ Doutora em Psicologia Social Clínica - Universite de Paris VII. Pos-doutorado em Sociologia. Professor Titular da Universidade Federal Fluminense. 
Entrevistadores: Eduardo Passos; Estela Scheinvar; Marisa Rocha;

Maria Livia do Nascimento; Silvia Tedesco; Teresa Cristina Carreteiro

podem ser considerados como máquinas de produzir novas subjetividades profissionais e ao mesmo tempo uma sobreimplicação nessa profissão, porque acreditar que vamos ultrapassar essas dificuldades práticas através do discurso, pela troca do discurso é, ao mesmo tempo, uma maneira de ser sobreimplicado na profissão. Então, essa sobreimplicação reflexiva tem uma contradição em um nível e uma grande complementaridade em outro nível. Racionalmente é uma contradição, mas institucionalmente é bastante complementar. Isso vai se vincular à idéia de transdução e de individuação.

Se eu falo de implicação profissional é porque eu considero que a individuação do profissional se faz transdutivamente em relação à individuação da própria profissão. As profissões estão se individuando no tempo, em uma sociedade política que não é qualquer uma, mas naquela na qual o poder neoliberal triunfou. Essas profissões vão se apoiar muito sobre o modelo das profissões liberais, nas quais os indivíduos são tidos como autônomos e responsáveis. Ele deve, livremente, ser o sujeito da sua profissão e deve fazê-lo de forma inteligente, porque deve mobilizar o saber universitário que está à sua disposição. $\mathrm{O}$ indivíduo e a profissão vão se individuar pelo mesmo processo.

Isso pode ser claramente visto quando pensamos sobre a ética. Em todas as profissões que eu analisei, se fala de ética profissional. Anteriormente, falavase da moral profissional. A moral deve ser respeitada por aquele que exerce uma atividade profissional. Ela coloca uma estrutura de trabalho. Sabe-se o que se pode e o que não se pode fazer. Com a idéia de uma ética profissional muda-se de sistema. É a profissão que deve elaborar permanentemente uma ética, que deve levar em conta as evoluções científicas, por exemplo, na medicina. Deve levar em conta, também, as evoluções políticas e ideológicas. Por exemplo, para os educadores se levar em conta a idéia que se tem sobre criança Essa ética não é estática, como a moral podia ser. Ela é dinâmica, ela se individua no tempo, num processo que é ao mesmo tempo coletivo e individual. A profissão vai sendo construída pelos profissionais da profissão, mas com uma interferência permanente com outras profissões, com a universidade, com a política, com os saberes, etc. $\mathrm{O}$ indivíduo que pertence a essa profissão participa, pois, dessas novas elaborações, mas ele também é o sujeito. Ele deve se inscrever numa dinâmica permanente, suas referências vão se modificar continuamente. É isso que vai perturbar muito os profissionais que se formaram há 20, 30 anos.

A reflexibilidade é considerada como um conceito mágico, que permite ao indivíduo permanecer em permanente interação com a sua profissão. Ele deve analisar continuamente sua prática, que evolui porque seu público (alunos, doentes etc.) evolui. As práticas, as técnicas evoluem cada vez mais rapidamente, o contexto de sua prática também evolui. Por exemplo, no contexto jurídico as crianças têm novos direitos e muitos profissionais se sentem confusos com esses novos direitos. Em suma, a prática se movimenta, o contexto das práticas se movimenta e a capacidade universitária do profissional lhe deve permitir analisar essas mudanças contínuas, mas ele deve fazê-lo no interior de sua própria profissão, de maneira que possa se beneficiar do suporte da sua profissão. Ele vai utilizar o saber profissional da sua profissão na sua própria prática individual e vai benefi- 
ciar sua profissão com as suas análises. Então, existe uma dinâmica permanente que é sem dúvida uma revolução na maneira de considerar a prática. A implicação profissional é, pois, essa relação entre um indivíduo, cuja prática está evoluindo, e uma profissão que também está evoluindo. Tudo isso, no interior de um contexto sócio-econômico político que igualmente evolui. Quando falamos da extração da mais valia, podemos notar que mais reflexibilidade não vai ser acompanhada necessariamente de mais análise crítica, porque o indivíduo profissional vai pensar e analisar no interior do limite de sua própria profissão. Profissão que vai se tornar uma instituição, no interior da sua instituição profissional. Quanto mais essa profissão se individua mais se torna forte e vai ser difícil para o profissional pensar fora dessa profissão. A análise institucional, então, torna-se urgente, mas os diferentes tipos de clínicos são, eles próprios, profissionais e estão, também, capturados por suas sobreimplicações.

Entrevistadores: O encontro de Lourau com Simondon permitiu que ele pudesse fazer essa clínica do conceito de implicação, que para ele tinha sido capturado. Ele se refere a um sentido devocional, teologal desse conceito: implique-se, eu me implico, você está implicado, não estamos implicados... Ele vai mostrar como isso se tornou, nas mãos do capitalismo, uma forma de extração de mais valia, exigindo o que vai chamar de sobreimplicação. No início dos anos de 1990, Lourau encontra com Simondon, lê Simondon, pega o conceito de transdução, de individuação para falar de uma dinâmica contínua, e falando da dinâmica contínua está querendo salvaguardar o conceito de implicação Quando ele usa Simondon e a idéia de um processo de individuação, um processo dinâmico transdutivo, é para falar da implicação e se afastar da sobreimplicação. O que você está nos mostrando é que esse processo transdutivo foi capturado pelo capital. Ele já está submetido a uma nova forma.

Entrevistadores: Algo que me chama a atenção nesse processo de universitalização é pensar na reflexibilidade como algo que harmonizasse ou pudesse de alguma forma trazer progresso ou, portanto, trouxesse uma harmonia entre o fazer e o dizer, a prática do fazer e a prática do dizer. Como se elas se colassem, e na verdade elas não se colam nunca. Há sempre uma perturbação entre esses dois planos, que só ilusoriamente se tocam. Talvez essa incompatibilidade entre o fazer e o dizer, também contribua para essa sobreimplicação. Essa perturbação do profissional que não consegue dizer sobre o que faz. Ele faz, mas o dizer sobre o fazer muitas vezes perturba o profissional. Então, a reflexibilidade não é um esclarecimento sobre o que se faz, é uma perturbação. Produz perturbação.

Gilles Monceau: No conjunto dos discursos sobre a profissionalização há, efetivamente, uma redução, uma tendência à diminuição da distancia entre a prática e da teoria. Esta aposta no desaparecimento da distância entre a prática e a teoria é necessária para o desenvolvimento desse processo de profissionalização. Entretanto, atualmente, começamos a identificar sérios limites nessa aposta.

Nas intervenções que realizo, encontrei profissionais que consideram que apenas o discurso não é suficiente. Consideram que o discurso, a análise discursiva lhes permite a análise de suas práticas, mas sabem que isso não vai necessariamente 
Entrevistadores: Eduardo Passos; Estela Scheinvar; Marisa Rocha;

Maria Livia do Nascimento; Silvia Tedesco; Teresa Cristina Carreteiro

lhes fornecer os meios para transformar a prática. Por exemplo, nos institutos de formação de professores encontramos muitos professores jovens que são reflexivos, que têm grande destreza nos conceitos, no discurso, na escrita, mas suas práticas não têm grande qualidade. Alguns daqueles que formam esses professores estimam que eles possam ser até mesmo um pouco perigosos. Parece que querendo aproximar a teoria e prática, para evitar uma hierarquia entre a teoria e a prática talvez tenhamos nos privado da singularidade da prática. Além disso, atualmente, certos sociólogos do trabalho ou psicólogos do trabalho produzem pesquisas que se interessam pelos atos e pelos gestos e procuram o sentido e o valor escondido nos atos e nos gestos profissionais. Inversamente, me parece que querendo confundir teoria e prática, a teoria interroga cada vez menos a prática. Quanto mais tentamos articulá-las, menos a distância que pode existir entre elas vai poder produzir análise. Entretanto essas palavras são um pouco ardilosas, porque ao mesmo tempo em que podemos seguir esse raciocínio anterior, posso dizer também que a teoria pode se confundir com a prática, pois existe uma teoria na prática e a prática é uma teoria. Por isso, afirmo que as palavras são ardilosas. O que é certamente perigoso é confundir teoria com universidade, pois os universitários não são certamente aqueles que então no melhor lugar para elaborar uma teoria da prática de certa profissão. É por isso que participo de um movimento que visa reconhecer o lugar do profissional pesquisador. Oriento estudantes que já são profissionais, no setor da educação, no trabalho social, que vêm à universidade para refletir, analisar suas práticas profissionais. Eles vêm busca metodologias e meios de teorizar, mas não vêm procurar uma teorização que já esteja completamente feita e não esperam que os professores da universidade façam uma teorização da prática que eles já têm. Quando isso acontece é muito alienante para esses profissionais.

Entrevistadores: Penso que atualmente, em função do alto nível de desemprego, estamos criando a categoria do estudante profissional. Estudantes que vão ficando na universidade por muitos anos, financiados por bolsas, e ao saírem não têm uma prática como profissional, apenas como pesquisadores. Nós, formadores universitários, temos que pensar nisso. A máquina universitária está criando esse tipo de modelo.

Entrevistadores: O produtivismo que temos hoje na universidade se produz junto com o tarefismo do professor. Cada vez mais as turmas estão cheias. As mudanças vêem da administração, Muda o governo mudam as diretrizes educacionais. Nas nossas escolas existe um grande tarefismo e na universidade também. Quando faço pesquisas nas escolas vejo que os professores querem pensar, refletir sobre o que está ocorrendo. Eles querem refletir sobre como fazer, mas isso é difícil para eles porque falta tempo. Acredito que a administração não se está vivendo o mesmo tempo que os professores. São coisas diferentes. Trabalhar na escola é muito difícil, pois é preciso criar dispositivos de contra movimento, para criar espaços de pensamento, para produzir análises de implicações, para analisar as instituições, para transformar as experiências em conhecimento. Acho que a luta é tentar conseguir espaços e tempos dentro da escola, onde a experiência vivida, até mesmo o que não dá certo, possa ser um dispositivo de mudança. São as coi- 
sas que não funcionam muito bem que podem nos dar a oportunidade de pensar, mas se não há tempo para pensar as escolas vão acumulando fracasso escolar. $O$ fracasso escolar impossibilita pensar sobre as experiências, sobre as coisas que não funcionam muito bem. Não adianta o pesquisador ficar em sua sala, na universidade, produzindo inúmeras teorias sobre como vamos acabar com o fracasso escolar. É preciso sair desse espaço, não adianta ficar pensando o fracasso escolar de fora é preciso entrar nas escolas para poder pensá-lo.

Gilles Monceau: Sabemos que, atualmente, as coisas não vão indo bem nos estabelecimentos educativos, médicos ou sociais. Os profissionais se queixam da violência, os administradores se queixam de problemas de gestão, os que fazem a gestão se queixam dos educadores e os educadores se queixam dos que gerenciam, e todos se queixam do Estado. Acredito que essas queixas não são novas. Tais questões sempre foram objeto de atuação da Análise Institucional e da Psicossociologia. Quando algo não funciona bem, quando há sofrimento, nós chegamos como abutres. Isto é um elemento constitutivo da análise de nossas implicações. Ver que prosperamos e trabalhamos com o sofrimento, mas esse sofrimento é também para nos uma oportunidade de produzir novas análises sobre o estado das instituições e ao mesmo tempo, trabalhando com as pessoas que estão nesse estado de sofrimento, tentar buscar vias alternativas. Não existe fatalismo. Realizei uma intervenção em um grande estabelecimento educativo onde os professores se queixavam da violência das crianças. Após um ano de trabalho e com um dispositivo bem complexo, constatamos junto com os profissionais que a dificuldade mais importante não era as crianças. A grande dificuldade e o sofrimento vinham das novas técnicas de educação e também das técnicas psicológicas. $O$ título do nosso relatório final foi "O limite da individualização". Porque constatamos, junto com os profissionais, que havia para eles uma urgência em reconstruir outras práticas de educação mais coletivas e que integrassem dispositivos de análise política, em particular as que fizessem compreender as evoluções.

Outro elemento se refere à prática do pesquisador. Algo que faz parte de meus pequenos combates, o pesquisador ou o professor que está na universidade é também um prático. Ele tem uma prática profissional, uma técnica profissional, ele também tem uma alienação que ocorre em seu gabinete. Os professores universitários não estão fora das instituições, se não a vida seria bem mais fácil e nós poderíamos pretender a objetividade quando trabalhássemos na escola, mas não é o caso.

Entrevistadores: A universidade é uma máquina que produz diplomas. Não existe tempo para outras coisas.

Gilles Monceau: O que você está dizendo é também uma contradição das novas formas de formação profissional. A questão que você coloca para a psicologia, na França, encontramos na formação de professores. Falo de uma maneira rápida e técnica. Hoje, na formação de um professor da escola primária, na formação inicial existem 150 horas de análise de prática, mas esses estudantes não têm prática. Isso é um problema. Então, no interior dessas 150 horas vão ser inventadas algumas coisas. Existem mesmo estágios aonde os estudantes vão às escolas. 
Entrevistadores: Eduardo Passos; Estela Scheinvar; Marisa Rocha;

Maria Livia do Nascimento; Silvia Tedesco; Teresa Cristina Carreteiro

Entretanto, o que esse estudante pode fazer nesse estágio, se ele não tem realmente a responsabilidade da classe o ano todo. Isso não corresponde verdadeiramente ao que seria sua prática profissional. Sua relação com a instituição é radicalmente diferente. É toda uma questão de analisar essa prática, construir essa reflexão quando na verdade ele não tem uma prática. Então, no discurso oficial isso existe. Diz-se que essa reflexão é uma competência, que o estudante vai se formar mesmo sem ter a prática e que depois ele a terá. É uma maneira de treinar a reflexão. Existem, pois, muitas contradições nesse sistema. A máquina não funciona sempre muito bem.

Entrevistadores: Essa lógica se dá na escola, mas também na universidade. A universidade analisa os equipamentos sociais, mas não analisa suas próprias práticas e não as analisa porque vai aos equipamentos sociais para produzir textos, para não refletir sobre sua prática na universidade. Na verdade, é uma prática que segue a mesma forma presente na escola ou no hospital. Trabalho numa faculdade de formação de professores. O grande modernismo é formar professores reflexivos. Isso é o que existe de mais moderno no discurso pedagógico, coletivamente, institucionalmente falando. Os alunos vão lá para se tornarem reflexivos. Uns já trabalham, outros não. Quem vai formar esses alunos reflexivos é uma pessoa que nem conhece necessariamente, intimamente o campo de trabalho. Às vezes têm menos intimidade que o aluno. É muito interessante trabalhar com as ferramentas da Análise Institucional porque ela leva a uma produção coletiva e eu acho importante o que você traz sobre a análise de implicação. O fato de que ela é sempre coletiva e para ela acontecer tem-se que produzir análises internamente, no lugar onde ela está e necessariamente do lugar de onde se vem. Acho que é uma tensão e um paradoxo, porque a Análise Institucional acaba sendo uma proposta, uma metodologia de trabalho que vem da academia e uma academia que não se discute, não se analisa sistematicamente, institucionalmente. Então, eu acho que há sempre uma tensão. Uma tensão que eu vejo que alguns grupos mais críticos nos cobram. Quem são vocês? Vocês se analisam? De que lugar vocês falam? Na minha experiência no Conselho Tutelar, eles fazem esse tipo de pergunta.

Gilles Monceau: Para mim o conceito de resistência é um muito importante e foi sobre ele que eu fiz minha tese de doutorado. Parecia-me que esse conceito poderia ser muito útil para a análise, mas lendo pesquisas da área das Ciências Humanas, percebi que muitas vezes as resistências eram consideradas numa perspectiva negativa. De forma resumida, aquele que resiste pode ser considerado um insensato. Ele resiste porque não compreende. Operários resistem porque não compreendem a nova forma de organização, não compreendem que é preciso que a produção aumente. Os alunos que recusam a escola são insensatos porque não compreendem que da escola dependem seus destinos social e profissional. Poderia multiplicar esses exemplos Em todas essas resistências, quer seja no espaço do trabalho industrial, na escola ou em outros, os sociólogos, os clínicos de todo tipo, muitas vezes, não vêem a potencialidade existente nas práticas de resistência. Quando estou trabalhando em uma intervenção sócio-clínica, uma questão crucial para mim é saber o que querem aqueles que não querem. Aqueles que resistem a novas transformações, a um discurso, onde eles querem ir? Ou mais 
simplesmente, onde eles estão indo? É sobre esse ponto preciso que a implicação do pesquisador, do clínico é importante. Se eu, enquanto pesquisador, penso que essas pessoas devem adotar o que está sendo proposto, devem obrigatoriamente ser escolarizados, no caso da escola, por exemplo, eu não posso compreender nada do que se passa nessa situação, porque a idéia é que a análise vai emergir nessa perturbação. Então, as resistências são analisadores. Elas ativam contradições institucionais. Quando os educadores não querem adotar as novas modalidades de pensar, eles estão defendendo outras coisas, outros valores, outras práticas. Posso estar ou não de acordo com elas, mas, além disso, existe a análise. Eu não vou aos estabelecimentos para ter colegas, não vou lá para encontrar camaradas de luta. Eu vou buscar camaradas de análise. Podemos ter conflitos. 